\title{
Validity and Reliability of the Hindi Version of the Modified Child Perceptions Questionnaire 11 to 14
}

\author{
${ }^{1}$ Prasanna Kumar, ${ }^{2}$ Dempsy CM Mandanna, ${ }^{3}$ Sanjay M Londhe, ${ }^{4}$ Mohit Sharma
}

\begin{abstract}
Introduction: The study was conceived to formulate a tool to evaluate child perceptions related to oral health in 11- to 14-year-olds tailor-made for Indian children in Hindi. The original child perceptions questionnaire $\left(C P Q_{11-14}\right)$ was translated into Hindi and it was tested for validity and reliability.

Materials and methods: The original $C P Q_{11-14}$ was translated into Hindi and some questions were rephrased to suit the sociocultural situation in India. The domains of self-esteem and psychological well-being were added to the questionnaire to broaden the scope of parameters to thoroughly assess the impact on child perceptions toward oral health. The English and Hindi versions of the $C P Q_{11-14}$ were administered during the first visit to test for validity and the children were recalled after 1 week and administered the Hindi questionnaire again after 1 week to check for reliability.
\end{abstract}

Results: The results showed significant positive correlation between oral symptoms, decayed, missing and filled teeth (DMFT) functional limitation and malocclusion. The mean functional limitation score was found to be higher in subjects with malocclusion in both the English and Hindi questionnaires. The test-retest samples were evaluated using the paired t-test and showed no significant difference between the first and second administration which suggested good reliability.

Conclusion: The translated and modified Hindi $\mathrm{CPQ}_{11-14}$ was found to be valid and highly reliable for use in India. The adaptation of the original questionnaire by modifying certain questions to suit the Indian condition was found to be culturally relevant.

Keywords: Child perceptions questionnaire, Hindi version of child perceptions questionnaire 11-14, Validity and reliability of child perceptions questionnaire 11-14.

How to cite this article: Kumar P, Mandanna DCM, Londhe SM, Sharma M. Validity and Reliability of the Hindi Version of the Modified Child Perceptions Questionnaire 11 to 14. Int J Clin Pediatr Dent 2018;11(4):271-276.

\footnotetext{
${ }^{1,3}$ Professor, ${ }^{2}$ Assistant Professor, ${ }^{4}$ Associate Professor

${ }^{1}$ Department of Dental Surgery and Oral Health Sciences, Armed Forces Medical College, Pune, Maharashtra, India

${ }^{2}$ Department of Pedodontics, Armed Dental Centre (R\&R), New Delhi, India

${ }^{3,4}$ Department of Orthodontics, Armed Forces Medical College Pune, Maharashtra, India
}

Corresponding Author: Prasanna Kumar, Professor Department of Dental Surgery and Oral Health Sciences, Armed Forces Medical College, Pune, Maharashtra, India, Phone: +919673135335, e-mail: drprasannamp@gmail.com

\section{Source of support: Nil}

Conflict of interest: None

\section{INTRODUCTION}

The general health of an individual is influenced by the state of the oral health, thus impacting the overall quality of life (QoL). ${ }^{1}$ This has been brought out aptly in the definition of health given by the World Health Organization, which defines health as a state of complete physical, social and mental well-being. The QoL is defined as an individual's perception of their position in life in the context of the culture and value system where they live and in relation to their goals, expectations, standards and concerns with regard to their health. . $^{2,3}$

Oral health-related quality of life (OHRQoL) is a measure which helps in assessing the functional and psychological impact of oral diseases on individuals. The importance of these tools can be appreciated while evaluating oral health of individuals and communities, making clinical decisions or evaluating success of interventions and also to assess oral health programs and services. ${ }^{4,5}$ Therefore, measurement of OHRQoL can be an important tool for use in community-based oral health surveys. ${ }^{6,7}$

Children are affected by various disorders in the oral and orofacial region, such as malocclusion and dental caries which can potentially compromise social, emotional well-being, and function impacting the OHRQoL. ${ }^{8,9}$ These disorders of orofacial function can affect vital functions, such as breathing, chewing, swallowing, and muscle posture which are important for proper speech, communication and facial expression impacting the perception of OHRQoL. ${ }^{10,11}$ However, there are very few age-specific tools for measuring OHRQoL, especially in children and most of them are in English. This makes it unsuitable for use in populations where English is not spoken. The CPQ is an age-specific validated self-administered questionnaire for measuring OHRQoL developed originally in Canada in English. ${ }^{12,13}$ The CPQs evaluate OHRQoL in four domain subscales of oral symptoms, functional limitations, emotional well-being, and social well-being. The aim of this study was to translate the English version of the $\mathrm{CPQ}_{11-14}$ into Hindi to culturally adapt it to the Indian sociocultural situation and evaluate its comprehensibility, validity, and reliability. 


\section{MATERIALS AND METHODS}

The testing of the Hindi version of the $\mathrm{CPQ}_{11-14}$ was carried out on 40 children who came to our institute along with their parents for the first time seeking orthodontic treatment.

\section{Inclusion Criteria}

- 11- to 14-year-old children

- Understanding/speaking Hindi and English

- No cognitive impairment

- Informed consent from parent

- Assent from child

The $\mathrm{CPQ}_{11-14}$ contained questions on various domains; the first two collected demographic details (sex and date of birth). The third question was based on the condition of oral health which was rated according to the Likert scale with five choices ranging from excellent, very good, good, acceptable, or bad. The fourth question related to the extent to which the oral health affected the overall well-being, with choices ranging between not at all, very little, somewhat, a lot, or very much. The responses were scored on a scale of 0 to 4 .

The remaining questions were divided into four oral health-related domains, namely oral symptoms $(n=6)$; functional limitations $(\mathrm{n}=9)$; emotional well-being ( $\mathrm{n}$ =9); social well-being ( $n=8)$; self-esteem $(n=14)$; and psychological well-being $(n=16)$. Each question had five responses, namely never, once or twice, sometimes, often, and everyday or almost every day with scores ranging from 0 to 4 . The questionnaire contained a total of 62 questions and since they were scored based on scores assigned on the Likert scale, the highest possible score was 248 and the lowest, 0 . The scores for each subscale were calculated by adding the response scores for particular domain.

The institutional ethical committee clearance was obtained prior to the commencement of the study to rule out any ethical issues. An informed consent form was signed by the parents after they were explained the procedure of the study. Each child participating in the study was explained the procedure and his assent was taken.

A total of 40 questions was administered to the children who had knowledge of both English and Hindi and they were asked to complete the questionnaire without their parent's assistance. If a child was found taking the help of his parent, that questionnaire was discarded from the study. The child had to fill both the English and Hindi version of the questionnaire during the first visit to the clinic. The child was also clinically examined during this visit to record the caries status using the DMFT index. This index records the scores for each child depending on the number of teeth decayed or filled and missing due to caries. The teeth extracted for other reasons or missing congenitally, unerupted, or lost as a result of trauma are not included. The malocclusion status was also recorded and scored as follows: (0) No malocclusion, (1) slight or moderate, and (2) moderate to severe.

Since the children had visited the clinic along with their parents with the intention of undergoing orthodontic treatment, they were recalled after 1 week and readministered the Hindi version of the questionnaire to check for its reliability. The questionnaires with any question unanswered were excluded from the study and not sent for statistical analysis. Therefore, 7 questions which were incomplete had to be rejected, thus bringing the final sample to 33 .

\section{RESULTS}

The total number of children who completed the questionnaire and also successfully completed the retest Hindi questionnaire the second time were $n=33$, of which the total no of male children were $n=18(54.54 \%)$ and female children were $\mathrm{n}=15(45.45 \%)$. The clinical data showed that $72.7 \%$ of these children had some form of oral symptoms (DMFT), 45.4\% children had slight-tomoderate malocclusion, and $33.3 \%$ had severe malocclusion requiring active treatment. The statistical analysis of the results from all the questionnaires was carried out by testing the discriminant validity by first comparing total and subscale scores of the children with relation to their DMFT status and malocclusion scores. The total and subscale scores were calculated for the whole sample using the Spearman's rank correlation coefficient. The results of the discriminant validity testing for the English questionnaire showed significant positive correlation between oral symptoms, DMFT, and malocclusion. There was also significant positive correlation between functional limitation and malocclusion. The overall total score showed significant positive correlation with malocclusion (Table 1). The discriminant validity testing of the Hindi questionnaire in both the first and second administration showed significant positive correlation between functional limitations and malocclusion. The discriminant validity testing of the Hindi questionnaire also revealed a positive correlation between the total score and malocclusion (Tables 2 and 3).

Discriminant validity testing was also carried out with relation to overall and subscale scores for children with no malocclusion, with moderate malocclusion and severe malocclusion. The results revealed that the mean functional limitation scores were significantly higher in subjects with malocclusion than in subjects without malocclusion in both the English and Hindi questionnaires. Further, the independent sample " $\mathrm{t}$ " test brought out 
Validity and Reliability of the Hindi Version of the MCPQ 11 to 14

Table 1: Discriminant validity: rank correlations between DMFT, malocclusion (MO) index scores, and subscale scores (English)

\begin{tabular}{llll}
\hline & & $D M F T$ & $M O$ \\
\hline OS_E & $\mathrm{R}$ & $0.342^{*}$ & $0.415^{*}$ \\
FL_E & $\mathrm{p}$-value & 0.05 & 0.016 \\
& $\mathrm{R}$ & 0.013 & $0.522^{* *}$ \\
EW_E & $\mathrm{p}$-value & 0.943 & 0.002 \\
& $\mathrm{R}$ & 0.021 & 0.336 \\
SW_E & $\mathrm{p}$-value & 0.905 & 0.056 \\
& $\mathrm{R}$ & 0.101 & 0.334 \\
SE_E & $\mathrm{p}$-value & 0.574 & 0.057 \\
& $\mathrm{R}$ & 0.167 & 0.311 \\
PW_E & $\mathrm{p}$-value & 0.352 & 0.079 \\
& $\mathrm{R}$ & -0.012 & -0.191 \\
Total & $\mathrm{p}$-value & 0.949 & 0.287 \\
& $\mathrm{R}$ & 0.199 & $0.544^{* *}$ \\
& $\mathrm{p}$-value & 0.267 & 0.001 \\
\hline
\end{tabular}

${ }^{* *}$ Correlation is significant at the 0.01 level (2-tailed); ${ }^{*}$ Correlation is significant at the 0.05 level (2-tailed)

Table 3: Discriminant validity: rank correlations between DMFT malocclusion (MO) index scores, and subscale scores (Hindi 2)

\begin{tabular}{llcc}
\hline & & $D M F T$ & $M O$ \\
\hline OS_H2 & $\mathrm{R}$ & 0.140 & 0.125 \\
& $\mathrm{p}$-value & 0.438 & 0.487 \\
FL_H2 & $\mathrm{R}$ & 0.115 & $0.413^{*}$ \\
& $\mathrm{p}$-value & 0.524 & 0.017 \\
EW_H2 & $\mathrm{R}$ & 0.144 & 0.292 \\
& $\mathrm{p}$-value & 0.423 & 0.099 \\
SW_H2 & $\mathrm{R}$ & -0.045 & 0.267 \\
& $\mathrm{p}$-value & 0.804 & 0.133 \\
SE_H2 & $\mathrm{R}$ & 0.103 & 0.336 \\
& $\mathrm{p}$-value & 0.570 & 0.056 \\
PW_H2 & $\mathrm{R}$ & -0.042 & -0.121 \\
& $\mathrm{p}$-value & 0.818 & 0.502 \\
Total_H2 & $\mathrm{R}$ & 0.163 & $0.485^{\star *}$ \\
& $\mathrm{p}$-value & 0.365 & 0.004 \\
\hline
\end{tabular}

${ }^{* *}$ Correlation is significant at the 0.01 level; *Correlation is significant at the 0.05 level

that the values of the mean total scores were significantly higher in the subjects who had malocclusion as compared with those without malocclusion in both versions of the questionnaires (Table 4). The construct validity was determined by drawing rank correlations between total scales, subscale scores, and comparing it with global ratings of oral health and overall well-being scores in both the versions of the questionnaires. However, there were no significant correlations between domain and total scores and global ratings scale (Tables 5 to 7 ). The reliability statistics for the translated Hindi version of the $\mathrm{CPQ}_{11-14}$ revealed a Cronbach's alpha value of 0.852 for the total scale. The values ranged from 0.72 for oral symptoms, 0.77 for functional limitations, 0.85 for emotional wellbeing, 0.66 for social well-being, 0.82 for self-esteem, and 0.71 for psychological well-being. Thus, this brought out
Table 2: Discriminant validity: rank correlations between DMFT, malocclusion (MO) index scores, and subscale scores (Hindi 1)

\begin{tabular}{llcc}
\hline & & $D M F T$ & $M O$ \\
\hline OS_H1 & $\mathrm{R}$ & 0.226 & 0.191 \\
& $\mathrm{p}$-value & 0.206 & 0.286 \\
FL_H1 & $\mathrm{R}$ & 0.076 & $0.376^{*}$ \\
& $\mathrm{p}$-value & 0.673 & 0.031 \\
EW_H1 & $\mathrm{R}$ & 0.168 & 0.232 \\
& $\mathrm{p}$-value & 0.350 & 0.194 \\
SW_H1 & $\mathrm{R}$ & -0.016 & 0.148 \\
& $\mathrm{p}$-value & 0.929 & 0.412 \\
SE_H1 & $\mathrm{R}$ & 0.117 & 0.227 \\
& $\mathrm{p}$-value & 0.518 & 0.204 \\
PW_H1 & $\mathrm{R}$ & 0.042 & -0.056 \\
& $\mathrm{p}$-value & 0.818 & 0.758 \\
Total_H1 & $\mathrm{R}$ & 0.244 & $0.422^{*}$ \\
& $\mathrm{p}$-value & 0.171 & 0.014 \\
\hline
\end{tabular}

Correlation is significant at the 0.01 level (2-tailed); ${ }^{*}$ Correlation is significant at the 0.05 level (2-tailed)

Table 4: Discriminant validity: overall scores for malocclusion with difference in means (English, Hindi 1, Hindi 2)

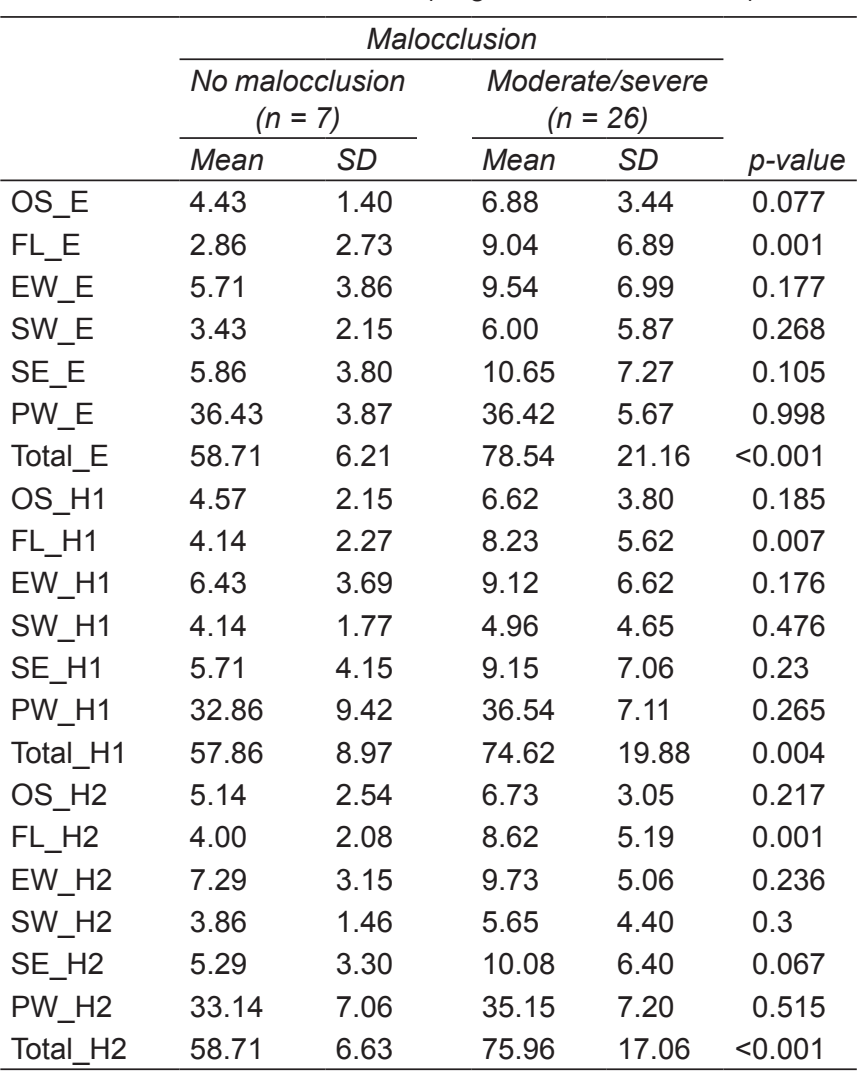

Independent sample "t" test; SD: Standard deviation

the fact that the Cronbach's alpha value for reliability was acceptable and suggested good internal consistency and correlation among the items in the translated Hindi version of the questionnaire (Table 8).

A paired $t$-test was also performed to check for testretest reliability of the Hindi questionnaire. It showed that only social well-being scores showed significant difference 
Table 5: Construct validity: rank correlations between total scale, subscale scores, global ratings of oral health and overall well-being (English)

\begin{tabular}{llrr}
\hline & & Q1_E & Q2_E \\
\hline OS_E & $\mathrm{R}$ & -0.050 & 0.107 \\
& $\mathrm{p}$-value & 0.782 & 0.552 \\
FL_E & $\mathrm{R}$ & -0.004 & 0.164 \\
& $\mathrm{p}$-value & 0.980 & 0.362 \\
EW_E & $\mathrm{R}$ & -0.063 & 0.198 \\
& $\mathrm{p}$-value & 0.727 & 0.270 \\
SW_E & $\mathrm{R}$ & -0.223 & -0.163 \\
& $\mathrm{p}$-value & 0.212 & 0.363 \\
SE_E & $\mathrm{R}$ & -0.160 & -0.067 \\
& $\mathrm{p}$-value & 0.373 & 0.710 \\
PW_E & $\mathrm{R}$ & 0.127 & 0.071 \\
& $\mathrm{p}$-value & 0.483 & 0.693 \\
Total_E & $\mathrm{R}$ & -0.112 & 0.084 \\
& $\mathrm{p}$-value & 0.535 & 0.642 \\
\hline
\end{tabular}

Table 7: Construct validity: rank correlations between total scale, subscale scores, global ratings of oral health and overall well-being (Hindi 2)

\begin{tabular}{llrr}
\hline & & Q1_H2 & Q2_H2 \\
\hline OS_H2 & R & 0.057 & 0.154 \\
& $p$-value & 0.752 & 0.391 \\
FI_H2 & $R$ & 0.034 & 0.070 \\
& p-value & 0.849 & 0.697 \\
EW_H2 & R & 0.003 & 0.011 \\
& $p$-value & 0.987 & 0.952 \\
SW_H2 & R & -0.061 & -0.134 \\
& $p$-value & 0.736 & 0.458 \\
SE_H2 & $\mathrm{R}$ & -0.106 & -0.259 \\
& $\mathrm{p}$-value & 0.559 & 0.146 \\
PW_H2 & $\mathrm{R}$ & 0.161 & 0.085 \\
& $\mathrm{p}$-value & 0.370 & 0.639 \\
Total_H2 & $\mathrm{R}$ & 0.054 & -0.041 \\
& $\mathrm{p}$-value & 0.767 & 0.821 \\
\hline
\end{tabular}

between first and second time tested Hindi version questionnaires, while rest of the domains and total scores showed no significant differences between first and second time testing which suggested good reliability (Table 9).

\section{DISCUSSION}

The study was conceived to formulate a tool to evaluate the perceptions of children in the 11- to 14-year-old age groups toward their oral health in general with major focus on DMFT and malocclusion, as these conditions are the most common among these children. The tool had to be understood by all the children and had to be socially and culturally relevant to the country where it had to be used. ${ }^{14-17}$ The $\mathrm{CPQ}_{11-14}$ is one such validated tool. This tool was, however, in English, which is a language alien to many children in India, especially those from rural backgrounds. The original $\mathrm{CPQ}_{11-14}$ was hence, modified
Table 6: Construct validity: rank correlations between total scale, subscale scores, global ratings of oral health and overall well-being (Hindi 1)

\begin{tabular}{llrr}
\hline & & Q1_H1 & Q2_H1 \\
\hline OS_H1 & R & 0.157 & 0.214 \\
& p-value & 0.382 & 0.232 \\
FL_H1 & $\mathrm{R}$ & 0.067 & 0.184 \\
& $\mathrm{p}$-value & 0.709 & 0.307 \\
EW_H1 & $\mathrm{R}$ & -0.167 & -0.100 \\
& $\mathrm{p}$-value & 0.353 & 0.580 \\
SW_H1 & $\mathrm{R}$ & -0.041 & -0.029 \\
& $\mathrm{p}$-value & 0.821 & 0.871 \\
SE_H1 & $\mathrm{R}$ & -0.087 & -0.115 \\
& $\mathrm{p}$-value & 0.631 & 0.523 \\
PW_H1 & $\mathrm{R}$ & 0.048 & -0.088 \\
& $\mathrm{p}$-value & 0.790 & 0.625 \\
Total_H1 & $\mathrm{R}$ & 0.009 & -0.018 \\
& $\mathrm{p}$-value & 0.960 & 0.919 \\
\hline
\end{tabular}

Table 8: Reliability statistics for total scale and subscales

\begin{tabular}{llll}
\hline & $\begin{array}{l}\text { Number } \\
\text { of items }\end{array}$ & $\begin{array}{l}\text { Cronbach's } \\
\text { alpha }\end{array}$ & ICC $(95 \% \mathrm{Cl})$ \\
\hline Total & 62 & 0.852 & $0.744(0.603-0.854)$ \\
OS & 6 & 0.728 & $0.668(0.456-0.816)$ \\
FL & 9 & 0.775 & $0.744(0.589-0.857)$ \\
EW & 9 & 0.854 & $0.849(0.758-0.915)$ \\
SW & 8 & 0.667 & $0.656(0.445-0.808)$ \\
SE & 14 & 0.82 & $0.813(0.704-0.895)$ \\
PW & 16 & 0.714 & $0.518(0.24-0.728)$ \\
\hline
\end{tabular}

$\mathrm{Cl}$ : Confidence interval; ICC, interclass correlation coefficient; $\mathrm{OS}$, oral symptoms; FL, functional limit score; EW, emotional well-being score; SW, social well-being score; SE, self-esteem score; PW, psychological well-being score

Table 9: Test-retest reliability of the Hindi questionnaire

\begin{tabular}{|c|c|c|c|c|c|}
\hline & \multicolumn{2}{|c|}{$H 1$} & \multicolumn{2}{|c|}{$H 2$} & \multirow[b]{2}{*}{$p$-value } \\
\hline & Mean & $S D$ & Mean & $S D$ & \\
\hline OS & 6.18 & 3.58 & 6.39 & 2.99 & 0.401 \\
\hline $\mathrm{FL}$ & 7.36 & 5.34 & 7.64 & 5.05 & 0.359 \\
\hline EW & 8.55 & 6.17 & 9.21 & 4.78 & 0.098 \\
\hline SW & 4.79 & 4.20 & 5.27 & 4.01 & 0.027; Sig \\
\hline SE & 8.42 & 6.65 & 9.06 & 6.16 & 0.059 \\
\hline PW & 35.76 & 7.65 & 34.73 & 7.11 & 0.092 \\
\hline Total & 71.06 & 19.30 & 72.30 & 16.94 & 0.17 \\
\hline
\end{tabular}

Paired "t" test; SD: Standard deviation; OS, oral symptoms; FL, functional limit score; EW, emotional well-being score; SW, social well-being score; SE, self-esteem score; PW, psychological wellbeing score

by adding questions on self-esteem and psychological well-being and translated into Hindi. In the Hindi questionnaire, some of the questions had to be rephrased as the exact translation would not be culturally relevant. This also helped to increase its usability to assess the perceptions of children in India. The translated tool needed to be validated and checked for reliability prior to its wider use in the population. The children who visited our institute for the first time seeking orthodontic treatment in the age group of 11 to 14 years were administered the English 
questionnaire followed by the Hindi questionnaire to check for its validity. The same group of children was recalled after 1 week and administered the Hindi questionnaire as a retest to confirm reliability. The children who did not complete the questionnaires or did not fill the consent forms were not included in the final sample. The parents of the children were requested to refrain from participating in the process of filling the questionnaires in order to prevent influencing the perceptions of the child. Some of the children found the questionnaire to be too long; however, that did not seem to affect its reliability or validity as shown in the results. The addition of the domains of self-esteem and psychological well-being contributed to the increase in questions as compared with the original English questionnaire. However, this addition helped to better evaluate the oral health status of the child with its influence on newer parameters of QoL.

The various tests for reliability showed significant positive correlation between malocclusion and functional limitation in both the English and the Hindi questionnaires. There was significant positive correlation between oral symptoms, DMFT, and malocclusion in the English questionnaire; however, there was no correlation found between the DMFT scores and functional limitations in any of the questionnaires. This was in line with other such studies done in United Kingdom and Saudi Arabia. ${ }^{18,19}$ The evaluation of perceptions related to QoL associated with oral health is strongly influenced by personality and standards of reference; therefore, poor correlations between these domain scores may actually be not so unusual.9,11

The construct validity of the Hindi questionnaire was found to be not so significant in relation to the domain scores, total score, and global ratings. These were found to be significant in the Saudi and Canadian studies; however, the sample size used in those studies was far bigger and this may help in bringing out association between the domains in the construct validity. Further, it has been brought out in previous studies that global rating of health can vary with the race, culture, and education. ${ }^{20}$

The reliability of the questionnaire was evaluated by test-retest samples of the translated Hindi questionnaire. The test-retest reliability of the Hindi questionnaire was found to be good $(0.17, \mathrm{p}<0.001)$ with significant differences found in the social well-being subscale. This could be because of the fact that the social well-being domain mainly dealt with the children's oral health and its impact on their relations with other children in school. Since the second retest administration was after 1 week, the child's perceptions of his relations to other children may have changed during the period.

The reliability was also evaluated using the Cronbach's alpha test which showed substantial internal consistency and correlation among the items in the Hindi questionnaire $(0.85, \mathrm{p}<0.001)$ which was similar to the Arabic (0.65, $\mathrm{p}<0.001)$ and English $(0.90, \mathrm{p}<0.001)$ language studies. ${ }^{18,19}$ The subscale scores were found to be satisfactory for validity when compared with the original English questionnaire; also the test-retest showed satisfactory reliability. The Hindi used in the translated version of the questionnaire is what is commonly taught to school children in India. As the spoken language may vary slightly with dialects used in different parts of the country, the written language is universal. This would help the applicability of the questionnaire in different parts of the country as was brought out with the studies done with the Arabic version in Syria, Egypt, and Saudi Arabia. ${ }^{18}$

One of the limitations of this study was in relation to the number of subjects; a larger group may have brought out more accurate results and will be attempted in the future. Further clinical examination was held with simple examination without the use of diagnostic tools like X-rays; therefore, dental diseases like dental caries were recorded only by visual examination. In the subsequent stage of the study, more accurate information will be recorded through more precise clinical diagnosis.

\section{CONCLUSION}

The Hindi translation and modification of the $\mathrm{CPQ}_{11-14}$ with addition of new domains to record perceptions of children toward oral health showed acceptable validity and reliability in the sample who were investigated at our institute. This tool will be helpful in wider multicentric studies on children in different parts of the country and also help in cross-cultural comparison of perceptions related to oral health among children in India and other countries.

\section{REFERENCES}

1. Petersen, PE. The World Oral Health report 2003: continuous improvement of oral health in the 21st century-the approach of the WHO Global Oral Health Programme. Community Dent Oral Epidemiol 2003 Dec;31(Suppl 1):3-23.

2. World Health Organization. Health promotion glossary. Geneva: World Health Organization; 1986.

3. Agency for Healthcare Research and Quality. Supporting research that improves health for children and adolescents. AHRQ Publication No. 00-P017. Rockville (MD): Agency for Healthcare Research and Quality; 2000.

4. Jokovic A, Locker D, Guyatt G. Short forms of the Child Perceptions Questionnaire for 11-14-year-old children (CPHQ11-14): development and initial evaluation. Health Qual Life Outcomes 2006;4:4.

5. Juniper, EF.; Guyatt, GH.; Jaesche, R. How to develop and validate a new health related quality of life instrument. In: Spilker B, editor. Quality of life and pharmacoeconomics in clinical trials. 2nd ed. Philadelphia (PA): Lippincott-Raven Publisher; 1996. pp. 49-56. 
6. Yamada H, Miura H, Usui Y, Sato T. Development of the Japanese version of the Child Perceptions Questionnaire (CPQ $\left.{ }_{8-10 \_} J P\right)$. Pediatr Dent 2013 Aug-Dec;23(2-3):86-90.

7. Streiner, DL.; Norman, GR. Health measurement scales: a practical guide to their development and use. Oxford: Oxford Medical Publications; 1994.

8. Department of Health and Human Services (U.S.). Oral health in America: a report of the surgeon general. Rockville (MD): Department of Health and Human Services (U.S.), National Institute of Dental and Craniofacial Research, National Institutes of Health; 2000. p. 322.

9. O'Connor, R. Measuring quality of life in health. Edinburgh: Churchill Livingstone; 2004.

10. Bakke M, Bergendal B, McAllister A, Sjogreen L, Asten P. Development and evaluation of comprehensive screening for orofacial dysfunction. Swed Dent J 2007 Feb;31(2): 75-84.

11. Rebok G, Riley A, Forrest C, Starfield B, Green B, Robertson J, Tambor E. Elementary school-aged children's reports of their health: a cognitive interviewing study. Qual Life Res 2001 Jan;10(1):59-70.

12. Jokovic A, Locker D, Stephens M, Kenny D, Tompson B, Guyatt G. Validity and reliability of a questionnaire for measuring child oral-health-related quality of life. J Dent Res 2002 Jul;81(7):459-463.

13. McGrath C, Alkhatib MN, Al-Munif M, Bedi R, Zaki AS. Translation and validation of an Arabic version of the UK oral health related quality of life measure (OHQoL-UK) in Syria, Egypt and Saudi Arabia. Community Dent Health 2003 Dec;20(4):241-245.

14. Hadzipasic-Nazdrajic A, Hadzimuratovic E. The BosniaHerzegovina version of the child perception questionnaire 11-14 (BH-CPQ 11-14). Med J 2012;18(1):37-41

15. Barbosa TS, Tureli MC, Gaviao MB. Validity and reliability of the child perceptions questionnaires applied in Brazilian children. BMC Oral Health 2009 May; $9: 13$.

16. Wogelius P, Gjorup H, Haubek D, Lopez R, Poulsen S. Development of Danish version of child oral-health-related quality of life questionnaires (CPQ8-10 and CPQ11-14). BMC Oral Health 2009 Apr;9:11-18.

17. Behling O, Law KS. Translating questionnaires and other research instruments: problems and solutions. In: Lewis-Beck MS, editor. Quantitative applications in the social sciences. Thousand Oaks (CA): Sage; 2000. pp. 1-70.

18. Brown A, Al-Khayal Z. Validity and reliability of the Arabic translation of the child oral-health-related quality of life questionnaire $\left(\mathrm{CPQ}_{11-14}\right)$ in Saudi Arabia. Int J Paediatr Dent 2006 Nov;16(6):405-411.

19. Marshman Z, Rodd H, Stern M, Mitchell C, Locker D, Jokovic A, Robinson PG. An evaluation of the child perceptions questionnaire in the UK. Community Dent Health 2005 Sep;22(3):151-155.

20. Krause NM, Jay GM. What do self-rated health items measure? Medical Care 1994 Sep;32(9):930-942. 